\title{
Divulgação científica, redes sociais e historiadores engendrando novas histórias: entrevista com Bruno Leal
}

\author{
The dissemination of scientific knowledge, social networks and \\ historians creating new histories: an interview with Bruno Leal
}

Entrevista com

\section{Bruno Leal Pastor de Carvalho \\ Editor, rede social Café História; doutorando, Programa de Pós- graduação em História Social/ Universidade Federal do Rio de Janeiro. \\ Largo São Francisco de Paula, 1 20051-070 - Rio de Janeiro - RJ \\ - Brasil \\ brunoleal2003@gmail.com}

Concedida a

\section{Jaime L. Benchimol}

Pesquisador, Casa de Oswaldo Cruz/ Fiocruz.

jbench@oi.com.br

\section{Roberta Cardoso Cerqueira}

Editora executiva, revista História, Ciências, Saúde - Manguinhos, Casa de Oswaldo Cruz/Fiocruz.

cardosoc@coc.fiocruz.br

\section{Camilo Papi}

Produção editorial, revista História, Ciências, Saúde - Manguinhos, Casa de Oswaldo Cruz/Fiocruz.

camilo@fiocruz.br

\section{Marina Lemle}

Jornalista, blog História, Ciências, Saúde - Manguinhos.

marinalemle@gmail.com

Casa de Oswaldo Cruz/Fiocruz

Avenida Brasil, 4365

21040-900 - Rio de Janeiro - RJ

- Brasil
BENCHIMOL, Jaime et al. Divulgação científica, redes sociais e historiadores engendrando novas histórias: entrevista com Bruno Leal. História, Ciências, Saúde - Manguinhos, Rio de Janeiro, v.22, n.3, jul.-set. 2015, p.1067-1079.

Resumo

A entrevista com o historiador e jornalista Bruno Leal trata da criação do blog Café História e da relação entre internet, comunicação e as atividades dos historiadores. Seu blog tornou-se um importante canal de divulgação de conteúdos sobre história, com referências de livros, dicas de filmes, eventos científicos e vídeos que se relacionam com a área. O entrevistado destaca a importância de ações que conjuguem comunicação e história, faz críticas à atual formação do historiador e afirma a necessidade de reformulação curricular que possibilite uma nova forma de produzir e divulgar o conhecimento histórico.

Palavras-chave: Café História; redes sociais; divulgação científica da história; história pública; Bruno Leal Pastor de Carvalho (1982- ).

\section{Abstract}

The interview with historian and journalist Bruno Leal deals with the creation of the Café Historia blog and the relationship between the internet, communications and the work of historians. His blog has become an important channel to promote historical material, with bibliographical references, helpful information about films, scientific events and videos related to this area. The interviewee stressed the importance of actions that combine communications with history, made criticisms of the current training given to historians and affirmed the need for curricular reform that enables new ways of producing and disseminating historical knowledge.

Keywords: Café História; social networks; science communication of history; public history; Bruno Leal Pastor de Carvalho (1982- ). 
Você poderia começar falando sobre o processo de criação da rede social Café História: quando e como surgiu a ideia, o que o motivou a criá-la e qual sua área de interesse na história, já que, além de administrar o Café, você está terminando seu doutorado.

Entre 2003 e 2008, eu cursei, simultaneamente, as faculdades de comunicação social (Escola de Comunicação/Universidade Federal do Rio de Janeiro, ECO/UFRJ) e de história (Universidade do Estado do Rio de Janeiro), dois cursos que têm uma aproximação muito grande.

Do ponto de vista tecnológico, esse foi um momento muito importante para o Brasil. Foi o momento da popularização da banda larga, do barateamento dos computadores, da chegada em peso de dispositivos móveis, principalmente dos celulares. Isso tudo era muito novo e muito incrível. Mas, enquanto na faculdade de comunicação vivíamos intensamente essas transformações, discutindo todos esses temas com os professores em sala de aula, no curso de história ainda predominava uma abordagem muito tradicional, que desconfiava da tecnologia. Eram realidades bem diferentes.

O que você achou do currículo da Escola de Comunicação da Universidade Federal do Rio de Janeiro? Havia uma preocupação em trazer para o curso o impacto dessa mudança acarretada pela velocidade da comunicação?

Existia um olhar muito crítico a respeito daquilo tudo que estava acontecendo. Tive um professor de filosofia, por exemplo, o Henrique Antoun, ${ }^{1}$ que se intitulava "cyber marxista"; ou seja, até leituras tradicionalmente mais críticas da sociedade capitalista se apropriaram de alguma forma daquelas transformações. A questão é que na história essas temáticas não tinham tanto espaço. Foi quando decidi criar um projeto que conectasse minhas duas formações. Primeiro, fiz uma série de blogs, que, por vários motivos, não foram bem sucedidos. Comunidades em redes sociais já estabelecidas, como o Orkut, tampouco deram o resultado esperado. Em 2008, minha sorte mudou. Eu havia terminado as faculdades e trabalhava na Fundação Roberto Marinho. Sabendo que eu estava em busca de plataformas de criação de blogs, minha gerente de lá, na época, Eliane Birman, me apresentou uma rede social através da qual tomei conhecimento da plataforma norte-americana Ning, ${ }^{2}$ que permite a qualquer pessoa criar sua própria rede social, diferentemente do Facebook e Orkut, onde você só podia criar uma subcomunidade. O Ning é uma estrutura muito maior e com mais possibilidades. Ele foi criado em 2005 por Marc Andreessen, ${ }^{3}$ que desenvolveu o navegador Netscape nos anos 1990. O Ning tinha dois atributos importantes: estava disponível em língua portuguesa e era gratuito. Imediatamente vi que aquela ferramenta era exatamente o que eu estava procurando. Comecei, então, a construir a minha rede, o Café História. ${ }^{4}$

\footnotetext{
${ }^{1}$ Disponível em: http://www.pos.eco.ufrj.br/docentes/prof_antoun.html. Acesso em: 18 out. 2014.

2 “O que é plataforma Ning?” Disponível em: https://sites.google.com/site/profesuely/o-que-e-a-plataformaning. Acesso em: 18 out. 2014.

${ }^{3}$ Sobre Marc Andreessen, ver: http://www.biography.com/people/marc-andreessen-9542208. Acesso em: 18 out. 2014.

${ }^{4}$ Disponível em: http://cafehistoria.ning.com. Acesso em: 1 nov. 2014.
} 
O processo completo de criação, da elaboração dos primeiros conteúdos a estratégia de lançamento, levou três ou quatro semanas. Dei bastante atenção à questão do nome. Queria algo ao mesmo tempo universal, moderno e tradicional. A palavra café reúne tudo isso; lembra os cafés do século XIX, um lugar de encontro, de conversa e troca, mas também remete ao cybercafe de hoje, ponto de acesso à internet. Daí surgiu o nome, Café História. Em seguida, convidei mais ou menos cinquenta amigos para fazer uma navegação experimental pelo Café e me dar feedbacks. Isso ajudou a corrigir algumas falhas. Depois, concluída a identidade visual, lancei o Café História para o grande público. Desde então o projeto vem crescendo bastante.

Houve alguma ação específica no lançamento?

Eu comecei fazendo divulgação impressa. Imprimi mil flyers e os distribuí em lugares frequentados pelo meu público: museus, cinemas, faculdades, teatros, centros culturais etc. Não deu certo. Depois entendi: um produto on-line só vai ser bem acessado mediante divulgação on-line e não off-line, como tentei. Aposto que muita gente pegou o flyer e achou legal. Mas depois acabou esquecendo dentro da bolsa ou da mochila. Com a divulgação de link, isso não acontece. Se o sujeito se interessar, acessa na hora. Quando percebi isso corrigi minha estratégia. Divulguei em todas as listas de e-mail que conhecia e em todos os grupos de história do Orkut de que fazia parte.

O Café História foi lançado no dia 18 de janeiro de 2008. Com ele eu tinha um duplo objetivo: fomentar um espaço democrático para a troca de conhecimentos entre historiadores e divulgar a história para o grande público. Faltava naquela época um espaço de interação entre professores e pesquisadores de história na internet. O Café História vinha, dessa forma, ajudar a cobrir uma parte dessa lacuna.

Quando se pensa em divulgação científica, estamos falando de uma área já consolidada. Mas geralmente pensamos em biologia, física, química, astronomia etc. Raramente pensamos em sociologia ou história. Mas esse tipo de divulgação também é legítimo e igualmente valioso. O boom de revistas de história, tais como a Revista de História da Biblioteca Nacional e a História Viva, mostra o quanto esse campo é promissor.

Como você avalia hoje as características dessas interações que o Café História media? Como vê o desenvolvimento disso? As pessoas o procuram para divulgar coisas, conversam?

Acontece de tudo. Por exemplo: o Café História tem muitas parcerias com editoras. Cerca de 15 editoras, das universitárias às maiores do mercado, enviam-me mensalmente suas novidades. Diversos pesquisadores também enviam material para divulgação de cursos, eventos, de modo que hoje somos realmente uma plataforma de divulgação científica. O Café História está aberto a todo tipo de divulgação em história.

De certa forma o conteúdo vem até você. Hoje em dia você não precisa ser tão pró-ativo quanto no início?

É verdade. Mas ainda é fundamental ir em busca das pautas. Saber o que está sendo feito nas universidades, visitar os sites de museus, inscrever-se em malas diretas etc. Além disso, também procuro otimizar o material que alguns colegas me enviam: releases, flyers, programações etc. Em geral, não há uma preocupação estética com esse tipo de material. E eu 
diria que isso é essencial no trabalho de divulgação. Quando não consigo fazer esses ajustes, peço para que a pessoa faça, se possível. É algo bem colaborativo. Quando o material chega de novo, geralmente depois de passar por um designer, a divulgação decola. Em vez de ter 15 curtidas, temos quinhentas, não tem mais dois compartilhamentos, e sim quinhentos. Enfim, sempre tento sensibilizar as pessoas para a importância da apresentação visual do conteúdo.

Você alcança países latino-americanos? Já percebe como é seu alcance no exterior e a distribuição regional de sua rede?

Sim. Nos últimos três anos notei um crescimento significativo de acessos de Portugal, Cabo Verde e Angola. Acho que isso se deve ao fato de que nesses países também existe uma demanda muito grande por esse tipo de projeto em história. Ultimamente, o Café História tem ainda registrado muitos acessos da Argentina, Uruguai, Paraguai.

\section{Você consegue saber o perfil do seu público? Se é ou não formado em história?}

Há dois anos eu fiz uma pesquisa voluntária com pessoas que utilizam o Café História. Lembro-me que 89\% dos respondentes disseram ter cursado ou estar cursando graduação. Outro dado que me surpreendeu foi que, diferentemente de outras redes sociais, em que prevalece o jovem de 15 a 25 anos, no Café História a maior parte do público possui mais de 40 anos.

O levantamento em termos regionais mostrou que seguimos mais ou menos o mapa da exclusão digital do Brasil: muitos acessos são do Sudeste e do Sul, mas poucos vêm da região Norte. O Nordeste e o Centro-Oeste estão em posição intermediária. Nos dois primeiros anos da rede, o Rio de Janeiro ocupava o primeiro lugar em termos de acesso, mas foi ultrapassado

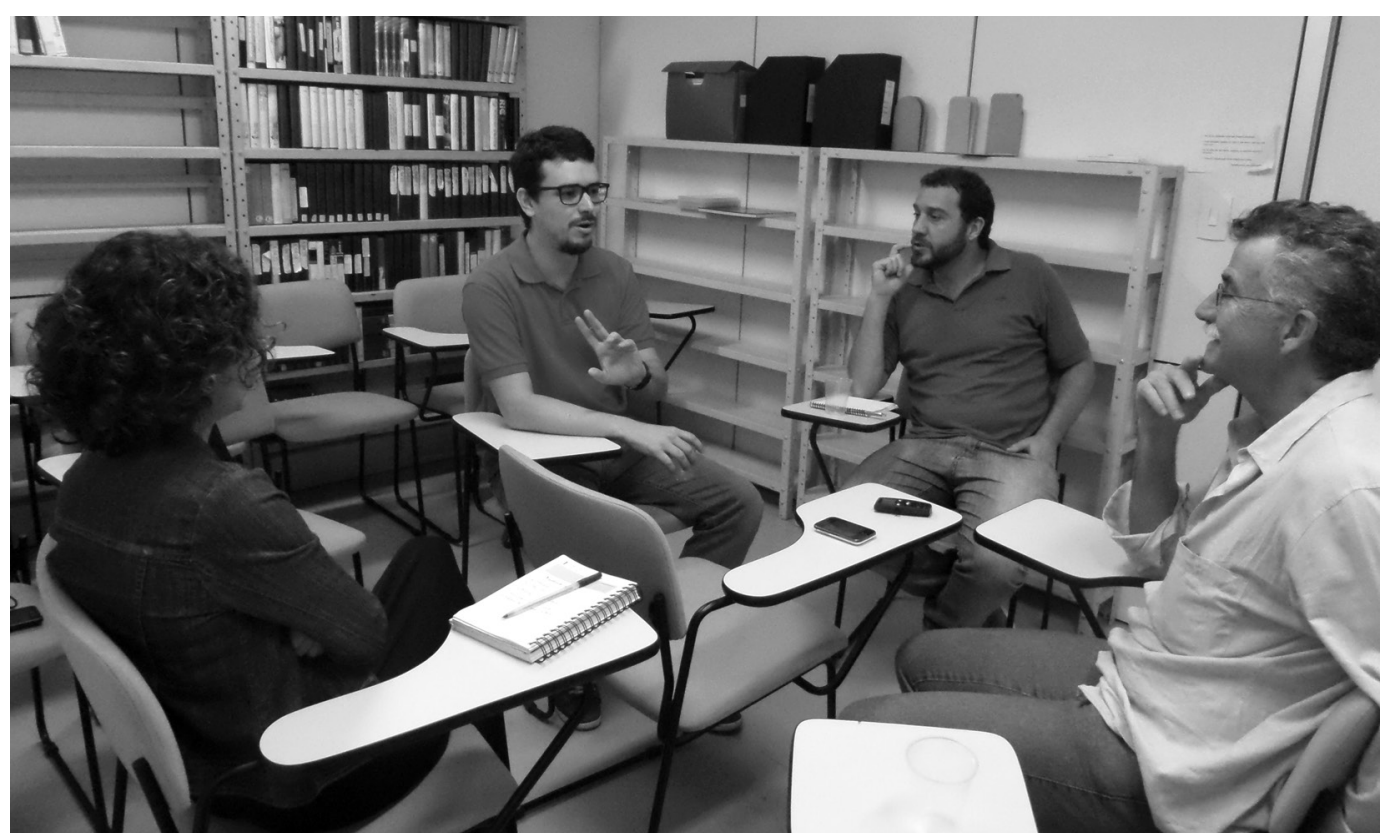

Figura 1: Bruno Leal (ao centro) em entrevista à equipe da revista História, Ciências, Saúde - Manguinhos (Foto de Marina Lemle) 
por São Paulo no terceiro ano de existência do Café História. Muitos usuários são professores, que depois de um dia inteiro dando aula ainda encontram tempo para ler suas mensagens e outros conteúdos do Café. Isso é incrível.

Você consegue diferenciar os usuários da newsletter dos das redes sociais?

Não consigo fazer essa diferenciação. Mas esses dois canais geram muitos acessos para o Café História. O Google e o Facebook se equiparam. O legal da newsletter, na minha opinião, é que ela funciona como um resumo do que foi atualizado na rede. Acho que por isso as pessoas apreciam o recebimento desse tipo de mensagem.

O perfil do seu público no Facebook corresponde ao do blog em termos de idade?

São usuários um pouco mais jovens, entre 25 e 35 anos. A maioria é de estudantes de graduação. Mas não sei quantas das 58 mil pessoas que estão hoje no Café História participam do Facebook. No Twitter, são vinte mil seguidores. Estamos também presentes em redes menores, como o Instagram, que usamos apenas para livros, e no Google Plus, rede do Google que parece não estar dando muito certo no Brasil.

É um publicador único ou tem que fazer publicações específicas para cada rede?

Eu faço questão de fazer publicações diferentes. Algumas são semelhantes. Mas em geral são distintas. Cada rede social possui particularidades e seus próprios públicos.

Você trabalha sozinho nisso ou tem uma equipe?

Adoraria ter uma equipe. As pessoas, às vezes, me escrevem dizendo que gostariam de conhecer a "sede" do Café História, sabe? Como se houvesse um prédio, uma redação. Acho isso o maior barato. Mas o Café História, infelizmente, não possui sede física. E a equipe que trabalha comigo é formada por colaboradores, professores/pesquisadores universitários que me enviam artigos ou concedem entrevistas. Esse tipo de colaboração acontece em uma nova seção, intitulada "Bibliografia comentada". Ela foi criada visando atender a uma demanda que havia para perguntas do tipo: "Poxa, eu quero começar a estudar Guerra do Paraguai, mas por onde começo?". A "Bibliografia comentada" funciona de maneira bastante simples: eu convido um historiador e ele comenta uma média de meia dúzia de livros fundamentais sobre um determinado assunto. Além desses colaboradores - sou muito agradecido a cada um! - conto ainda com a ajuda de minha esposa, Ana Paula Tavares, que é jornalista e atriz. Hoje ela é âncora do "História notícias", nosso web jornal no Café História TV.

O que é o Café História TV?

É um canal de vídeo que criamos no YouTube em novembro de 2013. Nosso vídeo de estreia foi um debate ao vivo sobre história digital. Além de mim, participaram dessa transmissão o Flávio Coelho Edler, da Casa de Oswaldo Cruz, as professores Lise Sedrez, da UFRJ, e Keila Grinberg, da Universidade Federal Rural do Rio de Janeiro. Cerca de quinhentas pessoas acompanharam a transmissão. Algumas participaram enviando perguntas, que foram respondidas ao vivo. Hoje, o canal possui cerca de quatro mil inscritos. 


\section{Tem um horário definido? Como é?}

Não, não tem horário definido. Eu explico. O Café História TV possui várias seções, como a "História notícias", nosso telejornal com notícias de história, e o "Cafezinho", que traz entrevistas com historiadores. Outra seção legal se chama "Nossa Lista", na qual elencamos sempre cinco itens de um assunto. Por exemplo: cinco filmes sobre história da Segunda Guerra Mundial. Ou, ainda, cinco sites de hemerotecas digitais. Outra seção muito interessante é a "O que é história?", em que fazemos essa difícil pergunta para grandes historiadores. Temos também uma seção de debates. Tentamos postar de dois a três vídeos por mês, mas é muito mais trabalhoso do que postar texto e áudio. Nem sempre conseguimos manter essa regularidade. Então, essa frequência varia bastante.

E o vídeo tem que ser presencial ou não?

Não necessariamente. Quando é possível, os vídeos são feitos presencialmente. Mas quase sempre fazemos tudo a distância. A tecnologia permite isso facilmente. Usamos como ferramenta o Google Hangout, uma espécie de Skype, que permite a transmissão ao vivo para uma grande audiência e necessita apenas de banda larga e webcam. Caso algum visitante do Café História não consiga acompanhar a transmissão ao vivo, o vídeo é automaticamente arquivado e pode ser visto depois.

\section{Como vocês se sustentam em termos financeiros?}

As pessoas volta e meia me perguntam se há retorno financeiro. Ele existe, mas é muito pouco. Quando falamos em projetos on-line é preciso correr muito atrás. É muito difícil capitalizar qualquer coisa na internet. O Google e o Facebook, por exemplo, tiveram vários problemas no início para tornarem seus negócios sustentáveis. O Ning, antes gratuito, hoje é pago. Já foi vendido duas vezes. Uma das formas que encontrei para tornar o Café História viável foi torná-lo parceiro do Google mediante um serviço chamado Google AdSense, que permite a inserção de publicidade. Além disso, também fazemos venda direta de espaço publicitário.

\section{E isso já é representativo?}

Em termos do Google Adsense, a cada click no anúncio, eu ganho uma porcentagem. Não é muito, mas o suficiente para cobrir as despesas operacionais. Há três anos eu ganhava dois terços a mais do que eu ganho hoje com publicidade por meio do Google AdSense, embora a minha base de usuários seja maior hoje. Isso acontece porque as pessoas já não clicam mais em publicidade.

\section{Quanto tempo você dedica ao Café História?}

Hoje já tenho uma rotina estabelecida, de modo que a minha manhã, geralmente, é dedicada ao Café História. O restante do dia dedico principalmente ao meu doutorado.

Qual o tema da sua tese?

No doutorado, trabalho com a questão dos criminosos nazistas no Brasil do pós-guerra. É um tema que foi durante muito tempo ignorado pela historiografia. Jornalistas, escritores, 
cineastas e pesquisadores independentes produziram muito a respeito. Mas os historiadores não. Isso, porém, vem mudando nos últimos anos. Eu me interesso sobretudo pela maneira como o governo brasileiro lidou com essa questão. Existe um discurso bastante difundido socialmente que afirma ter sido o nosso país, a exemplo da Argentina, um grande paraíso para criminosos nazistas, que aqui esses fugitivos da justiça internacional gozaram de uma vida nababesca, graças ao poder de redes nazistas internacionais e ao acobertamento das autoridades locais. De fato, alguns criminosos nazistas vieram para o Brasil no pós-guerra. Mas não sabemos ainda se esse número foi grande ou não. Sabemos menos ainda sob quais condições essas pessoas imigraram para o país e se tinham ou não cobertura do governo. Estou terminando minha tese e o que posso dizer é que essas leituras universalistas, totalizantes, por anos difundidas, sobretudo pela imprensa, não dão conta de explicar o fenômeno. É preciso checar caso a caso. Na minha tese, pesquiso especificamente o caso do imigrante Herberts Cukurs, o homem responsável por levar os pedalinhos para a Lagoa Rodrigo de Freitas. Cukurs, no entanto, se tornou conhecido mesmo por sua colaboração com os nazistas durante a ocupação do seu país natal, a Letônia. Ele chegou ao Brasil em 1946, e o escândalo envolvendo seu passado veio à tona em meados de 1950. Cukurs é o primeiro grande caso público de um alegado criminoso nazista no Brasil.

\section{Agora responda você: o que é história?}

É uma boa pergunta. Provando do meu veneno [risos]. Existe no senso comum a ideia de que história é sinônimo de passado. Eu acho que história é um trabalho intelectual a respeito do passado; um olhar, uma escrita controlada que produzimos para dar inteligibilidade ao passado. Ela envolve metodologias e estruturas que precisam passar pelo crivo dos colegas - que é o caso da banca, da orientação, dos colegas nas universidades. Isso é a história acadêmica: um tratamento intelectual do passado.

Ao longo desse tempo de funcionamento do Café História como você avalia o campo da história? Tem notado mudanças significativas?

Eu diria que este é um momento de muita transformação no campo da história. Estou cada vez mais convencido de que a comunicação é o elemento central dessa transformação. Na minha opinião, história é, antes de qualquer coisa, comunicação. Melhor comunicação produz melhor história. No Programa de Pós-graduação em História Social da UFRJ temos visto, por exemplo, que o cuidado maior na elaboração de nosso material de divulgação dos processos seletivos está diretamente relacionado ao número de candidatos inscritos nesses processos. E esse é apenas um aspecto mais concreto (e utilitário) de como a comunicação pode ser útil em ambiente profissional.

Aí você toca em um ponto nevrálgico, o fato de que poucos historiadores conseguem sair da linguagem esotérica, direcionada aos seus próprios pares. Você acha que essa é uma questão grave? Sua definição de história como "uma linguagem controlada pelos pares" é também uma camisa de força. O estímulo atual de produção de artigos é uma virada notável não só para a historiografia, como para outras áreas de humanas. Teve a voga das biografias... Você acha que há mais editoras publicando? 
A história é uma escrita controlada no sentido de que temos uma maneira de produzir o conhecimento histórico. É o que confere legitimidade ao discurso que produzimos e o que diferencia a história de outras abordagens e formas de produção de sentido sobre o passado. Não necessariamente melhor ou pior. Se esse controle vai ser uma camisa de força ou não, acho que depende de quem escreve essa história. Não precisa ser uma camisa de força. Agora, quando escrevemos para o grande público, essa escrita controlada precisa ser flexibilizada. Escrever para os pares é diferente de escrever para público mais amplo. Se você escreve para o grande público e não flexibiliza essa escrita, temos um grave problema. Falando sobre a produção de artigos, a oferta é muito maior hoje do que há cinco, seis anos. Hoje é possível fazer uma revista digital seguindo todas as regras acadêmicas. Esse modelo poupa gastos e permite alcançar enorme audiência. Hoje, temos um campo inteiro a explorar. Eu acho que quem nos mostrou muito bem isso foram escritores como Rui Castro, Eduardo Bueno e Laurentino Gomes. Independente da qualidade de suas respectivas obras, esses escritores encontraram um público disposto a consumir história. E alguns historiadores já fazem isso muito bem também, caso da Mary Del Priori, do Carlos Fico e do José Murilo de Carvalho. Para ampliar esse quadro precisamos ter mais atenção com o currículo universitário de história. Hoje se sai da graduação, por exemplo, sem saber o que é um release.

\section{Como você avalia a qualidade da escrita de um modo geral? Nota problemas?}

Tenho notado que muitos colegas ainda possuem muitas dificuldades para fazer seus trabalhos circularem fora da academia. Mas acho que melhoramos muito ultimamente. A Revista de História da Biblioteca Nacional trouxe um aprendizado enorme nesse sentido. Mas volto à questão do currículo: acho fundamental que a universidade inclua uma disciplina voltada para a divulgação científica, que trabalhe história digital, divulgação de história, história pública, seja optativa ou obrigatória. Essa disciplina teria a incumbência, por exemplo, de apresentar diversas modalidades de textos.

\section{Você consegue começar a propor alguma dessas cadeiras dentro da UFRJ?}

No programa de história social da UFRJ temos feito experiências interessantes, como, por exemplo, a criação de um canal no Youtube, o PPGHISTV. Atualmente, estou tentando montar um curso sobre história digital com o professor Ricardo Figueiredo de Castro. Há sim espaço para esse tipo de iniciativa. O Programa de Pós-graduação em História Social da UFRJ tem sido muito receptivo e muito propositivo. Tudo isso valoriza nosso trabalho.

Você acha que essa preocupação com a síntese, com a leitura dinâmica tem feito as pessoas perderem a paciência de ler os clássicos?

Não sei se estão perdendo... Desde Platão existe esta crítica: “a minha geração lia mais os clássicos". Acho que hoje lemos mais do que antigamente. Não tenho muitas dúvidas quanto a isso. Digo, lemos mais em termos gerais. Séries como As crônicas de gelo e fogo, de George R.R. Martin, e Harry Potter, de J.K. Rolling, fazem um enorme sucesso, principalmente entre os jovens. Para muitos, são portas de entrada para o mundo da literatura. Agora, acho que hoje, como antigamente, são poucos os que leem os clássicos. Pelo menos a maior parte dos 
clássicos. Livros como Dom Quixote sempre foram mais lidos por uma elite intelectual. Acho que continua sendo assim.

Bruno, você acha que as revistas deveriam deixar de ser publicadas em papel?

Em 1995, um colunista na Newsweek desdenhou do futuro da internet, dizendo que a web era uma tempestade num copo d'água, que não tinha futuro. Em dezembro de 2012, essa mesma revista deixou de publicar em papel e hoje está só na internet. Acho que para a grande mídia é um caminho quase irreversível. O número de impressões está cada vez menor. A minha geração é a última que está lendo muita coisa ainda em papel. Eu, particularmente, gosto mais de ler no papel. Não consigo me dar muito bem, por exemplo, com eBooks. Mas entendo que o futuro do mercado editorial é o digital. Não que o papel vá desaparecer. Longe disso, mas acho que o espaço dele será bem menor.

Não acha que para isso teríamos de resolver outras questões como o acesso deficiente à internet, mesmo num centro como o Rio de Janeiro?

Acho que isso é importante, claro; hoje existe desigualdade em termos de acesso à internet. Mas as pesquisas mostram que esse tipo específico de desigualdade está caminhando para o fim. Em breve, o acesso à internet deixará de ser um problema. A pergunta que devemos nos fazer, talvez, é se o livro ou a revista digital é simplesmente uma digitalização do material impresso ou se precisamos construir um modelo de publicação digital mais dinâmico. A revista da Livraria Cultura [Revista da Cultura] é muito interessante: você interage, tem vídeo, as fotos mudam o tempo inteiro. A Carta Capital também tem um modelo de revista digital bem interessante. Noto hoje ainda um paradoxo: ao mesmo tempo em que se fala muito em tecnologia e se vê essa enxurrada de novas mídias, parece também haver um movimento contrário, de volta ao passado. O vinil, por exemplo, está mais vivo do que nunca. Quem diria? Nada impede que daqui a vinte, trinta anos as revistas de papel e os jornais anunciem "a volta do papel".

Gostaria que fizesse uma avaliação rápida do segundo Simpósio Internacional de História Pública que ocorreu entre 10 e 12 de setembro de 2014, na Universidade Federal Fluminense (UFF).

O primeiro simpósio internacional de história pública aconteceu em 2011 na Universidade de São Paulo graças a um esforço interdisciplinar em desenvolver no Brasil uma discussão que já existia em países como Inglaterra, EUA, Austrália, que é a da public history, da história pública. Em 2014, trouxemos o segundo Simpósio Internacional para UFF. Fiquei positivamente surpreso com o número de pessoas que frequentaram os eventos, interessadas e empenhadas em fazer perguntas, estabelecer debates e criar novos canais para continuar discutindo história pública. Considero muito boa a qualidade das palestras. Temos ainda alguns desafios, como o de responder: "afinal de contas o que é essa public history?" Tudo, eu diria, começa por essa reflexão.

Você pode responder?

No simpósio nos fizemos essa pergunta em quase todos os espaços. É natural no momento em que vemos crescer o campo. Não sei se tenho uma resposta definitiva. Acho que é tão 
difícil quanto estabelecer o que é história. Mas vamos lá: entendo história pública como uma aproximação da história acadêmica com o grande público, fazer história fora da academia, mas com a academia. Isso, no meu caso, naturalmente engloba trabalhar com história digital e divulgação de história.

Mas é só o consumo da informação ou é produção também?

É produção também. História pública envolve a produção de textos originais, elaboração de novas metodologias de divulgação, de exposição de projetos voltados para o grande público. Desenvolver, por exemplo, um modelo mais dinâmico de revista acadêmica é de alguma forma fazer história pública. Desenvolver um projeto de tese a ser publicado numa editora, que vise não só a seus pares, mas ao grande público também é, de certa forma, história pública. Fazer uma rede social de história, como o Café História, é fazer história pública. Às vezes o conceito de

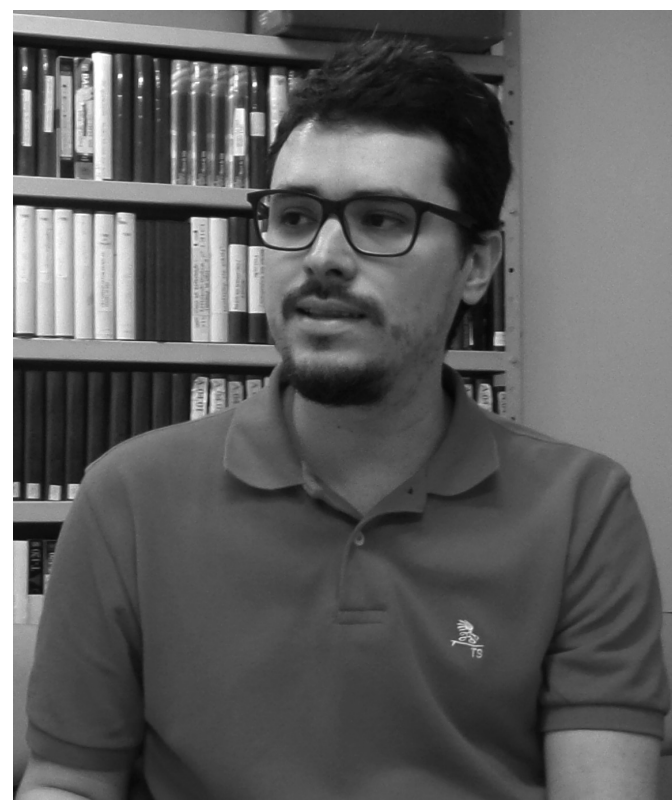

Figura 2: Bruno Leal (Foto de Marina Lemle) história pública se confunde muito com a divulgação de história. Em boa medida é divulgação de história, mas vai um pouco além. História oral também pode ser considerada história pública.

Li que o espírito inicial da história pública seria "empoderar" as pessoas para que fossem agentes da produção de sua própria história, como quando um indivíduo filma sua comunidade, ou seja, passaríamos a ser mais como coadjuvantes de atores leigos dedicados a produzir a sua história. Outras definições são aggiornamento do que a história sempre foi.

Em seu livro Sobre o tempo, o sociólogo Norbert Elias conta a história de um sujeito que dizia saber muito bem o que era o tempo, mas quando perguntado não fazia a menor ideia. Acho que com história pública vemos algo parecido. Eu sei exatamente o que é história pública quando não me perguntam. Reconheço o que faço como história pública. Mas não precisamos ficar muito obcecados em defini-la, precisamos apenas de alguns parâmetros. Vejo a história pública quando vou a um museu, biblioteca, arquivo, exposição e evento comemorativo. E se as pessoas tomam parte nesse processo, com certeza há um "emponderamento" da comunidade na construção da história. A propósito, acho que um grande desafio hoje é responder se a história pública é feita somente por historiadores, o que nos remete à questão do que é história.

Uma preocupação muito forte que surgiu quando as novelas começaram a investir nas temáticas históricas sem nenhuma preocupação com rigor e veracidade. Como ficam, nesse caso, os parâmetros de rigor e de fidelidade, e os mecanismos de controle?

É verdade, também encontramos problemas desse tipo. Nesse caso, podemos ver uma banalização da história, através de simplificações e reducionismos. Isso é muito problemático, sobretudo em um país tão problemático do ponto de vista educacional. Não sei dizer se 
conseguirmos ter controle sobre isso. No fundo, acho que se as pessoas são realmente emponderadas elas vão conseguir discernir uma boa obra de uma obra com qualidade duvidosa. Mas não precisamos ir muito longe quando nos referimos à questão do rigor. Até dentro da universidade isso também aparece como um problema. Veja o caso recente da Escola de Direito da Universidade de São Paulo, que ano passado deu dez a uma monografia que defendia o negacionismo do holocausto como uma forma de escrever história. O caso gerou enorme repercussão.

Você não acha que esses novos meios de comunicação talvez favoreçam essa tendência nefasta da ciência-salame, do plágio, da divulgação ad nauseum de versões do mesmo texto, enfraquecendo certas cláusulas éticas?

Talvez. Acho que a pressão de hoje pela produtividade é o principal responsável por isso. Para atingir os índices de produtividade, você muitas vezes apresenta um determinado trabalho sem que tenha havido avanço significativo na pesquisa. Esse modelo precisa ser repensado. Quanto ao plágio, a preocupação é enorme. Eu já fui membro de uma banca de monografia em que todo o trabalho tinha sido plagiado. E era a segunda faculdade do aluno. A UFF, há pouco tempo, disponibilizou gratuitamente em seu site uma espécie de manual antiplágio, orientando os alunos sobre o que fazer e o que não fazer na hora de escrever um trabalho acadêmico.

\section{Você acha que a internet pode ajudar nisso?}

Sim. Quando corrijo provas e desconfio de que um trecho de texto não foi escrito por aquele aluno, pesquiso no Google e em segundos o encontro.

Acho que tem de haver esforço e educação constantes de alerta sobre isso por parte dessas novas ferramentas de veiculação.

Quando falamos de internet, tudo ainda é muito novo. É um aprendizado duro, mas que tende a dar lugar a mecanismos mais claros de normatização. Por isso defendo tanto que os cursos de graduação em história ofereçam cadeiras destinadas à divulgação de história e história digital. É fundamental que os alunos aprendam a usar essas novas ferramentas de forma ética, responsável e consciente.

\section{Surgiram outros sites similares ao seu ou a sua iniciativa continua isolada nesse horizonte?}

Conheci algumas outras tentativas, incluída uma de plágio do Café História [risos]. Algumas pessoas que não concordavam com a política do Café História fundaram outra rede na mesma plataforma, com a mesma estratégia de distribuição dos conteúdos. Tudo era muito parecido. Mas não deu certo. E não deu porque o Café História não é apenas uma fórmula. Hoje, há muitas iniciativas interessantes, mas não conheço nenhuma outra rede social de história com as características do Café História.

Quais outras experiências você considera igualmente bem-sucedidas no nosso horizonte? Você tem interagido com iniciativas estrangeiras similares?

Vejo muitos perfis de programas de pós-graduação, de ministérios e de secretarias de Educação que possuem perfis em rede sociais, principalmente o Twitter. Acho isso muito 
bom. É uma forma de aproximar essas instituições da população. No Ning há uma rede da qual gosto muito, formada por professores americanos, chamada "Classroom 2.0". ${ }^{5}$ Acho incrível também o Academia.edu, que é uma espécie de Facebook para acadêmicos. Tenho usado bastante recentemente.

Voltando às iniciativas que você considera bem-sucedidas de divulgação da pesquisa histórica, como a Revista de História da Biblioteca Nacional, lembro que ela segue o modelo da Ciência Hoje, em que há jornalistas - especializados - que editam os textos enviados pelos pesquisadores. Você acha indispensável a presença deles ou o cientista tem que saber escrever em português claro?

Acho a presença do jornalista indispensável; é uma parceria muito importante e crucial para se alcançarem os melhores resultados. É alguém que vai se preocupar antes de tudo com a forma. É preciso evitar uma demonização do jornalismo e dos jornalistas.

Você acha necessária a divulgação dos artigos em resumos ou entrevistas, escritos em linguagem mais acessível, ou bastariam chamadas no Facebook direcionando sem mediação aos artigos publicados?

Acho que é uma possibilidade. No Café História, por exemplo, eu escolho um tema da semana, pesquiso artigos no Scielo ${ }^{6}$ e divulgo esses artigos no Facebook. Costuma funcionar muito bem. Quando publico algo diretamente no Café História, um artigo, digamos, sempre me preocupo em ter um texto mais curto e com linguagem mais acessível, mas sem perder profundidade.

Quais estratégias você recomenda para blogs de revistas científicas como o nosso, em vista da demanda para que as publicações passem a incluí-los em sua política de divulgação?

Acho que o blog precisa conversar muito com a revista. Esse link precisa estar muito claro para quem acessa o blog. Criar um canal no You Tube é uma ótima pedida. Esse canal poderia ser empregado para disponibilizar eventos produzidos pela casa. Isso seria fantástico. Tudo isso gera sinergia e fluxo de acesso entre os diferentes produtos.

Eu acredito em um tripé quando falamos em publicações na internet. Em primeiro lugar, está a qualidade do conteúdo. As pessoas querem conteúdo bom e confiável. Em segundo lugar, está a questão da atualização. O conteúdo precisa ser constantemente atualizado. A internet é muito dinâmica, muito viva. As pessoas esperam regularidade. Em terceiro lugar, mas não menos importante, está a questão da identidade visual. A primeira impressão é realmente aquela que fica: um projeto na web precisa parecer profissional, ter uma boa organização da informação, cores bacanas, cabeçalho, imagens; um bom produto, enfim, precisa ter apelo visual. A divulgação no Facebook, por exemplo, demanda muito esse destaque visual, pois você vai competir com uma série de outras publicações. A colaboração com o design gráfico é fundamental nesse sentido. Meu irmão é designer gráfico e me ajuda muito no Café História. Voltando aos vídeos, eles são ótimos, como eu disse, mas constituem algo mais

\footnotetext{
${ }^{5}$ Disponível em: http://www.classroom20.com/. Acesso em: 1 nov. 2014.

${ }^{6}$ Disponível em: www.scielo.br. Acesso em: 1 nov. 2014.

${ }^{7}$ Disponível em: http://www.revistahcsm.coc.fiocruz.br/. Acesso em: 15 jun. 2015.
} 
trabalhoso. É preciso estar atento a isso. No Café, temos uma sessão intitulada "Desembalando livros". Eu recebo o livro da editora e desembalo. É o famoso unboxing, que faz muito sucesso na internet. As pessoas fazem unboxing para tudo: de videogames e roupas. Todo mundo gosta de chegar em casa no final do dia e ter lá o livrinho que comprou, rasgar o papel e ver. O que eu faço é compartilhar isso com os leitores. Mas dá trabalho. Gasto cerca de uma hora para fazer um vídeo de cinco minutos.

A Escola Nacional de Saúde Pública (Ensp), por exemplo, investe pesadamente na educação a distância (EAD). Mas você acha que as iniciativas de divulgação ainda estão muito concentradas no eixo Rio-São Paulo?

Educação a distância é fundamental. Acredito muito em EAD. Principalmente para formação continuada de professores. Percebo que muitos profissionais sentem necessidade de encontrar espaços de trocas, de interação, de partilha de saberes. Talvez seja por isso que tantas pessoas escrevem para o Café História pedindo soluções para mil e uma coisas. A propósito da concentração, acho que talvez essas iniciativas ainda estejam mesmo muito concentradas no Rio e em São Paulo. Talvez. Mas há pessoas fazendo coisas incríveis em Santa Catarina, Pernambuco, Salvador.

Você responde a todas as demandas que surgem no Café História?

Tento responder na medida do possível. Mas há solicitações que parecem impossíveis, até mesmo engraçadas: pessoas que solicitam ajuda na identificação de pessoas e datas, que pedem fotos de cidade, ajuda com trabalho escolar e em monografias. Já recebi até e-mails de pessoas que me pedem ajuda para avaliar obras de arte e oportunidades de trabalho. Em vez de dar a resposta, que eu não tenho, sugiro que a pessoa abra um fórum de discussões, acesse determinado artigo ou entrevista publicada na rede ou dentro de algum grupo especializado do Café História. Procuro aproveitar ao máximo a força colaborativa do Café História. Essa é a ideia.

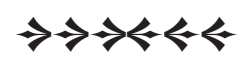

